\title{
Adsorption Removal of Rhodamine-B Dye From Aqueous Solution Using Rhamnus Stone as Low Cost Adsorbent
}

\author{
Khudhair. A. Al-Rudaini \\ General Directorate of AL-Rusafa the second Education, Ministry of Education, Baghdad-Iraq. \\ E-mail: Khudhair.2010@yahoo.com
}

\begin{abstract}
In this study, low-cost Rhamnus stone was used as adsorbents for the adsorption of Rhodamine$\mathrm{B}(\mathrm{RhB})$ dye from aqueous solution by batch experiments under different condition of adsorbent weight, contact time, $\mathrm{pH}$ and initial dye concentration. Kinetic data obeyed to Ho-Mckay pseudo second order equation. Freundlich and Langmuir isotherms were used to test the equilibrium data and the results shows better fit with Langmuir isotherm with maximum adsorption capacity $39 \mathrm{mg} / \mathrm{g}$. Thermodynamic parameters show the adsorption of $\mathrm{RhB}$ onto Rhamnus stone was spontaneous and endothermic. [DOI: 10.22401/JNUS.20.1.05]
\end{abstract}

Keywords: Rhodamine-B, Rhamnus stone, Adsorption, kinetic, Thermodynamic.

\section{Introduction}

One of the most important environmental problems faced the human in last century and current century are the treatment of waste water due to increasing in industrials chemical effluents such as heavy metals, dyes, pigments, and other organic and inorganic chemical compounds discharge to water resources [1]. Among these effluents, dyes get special concern from researchers because carcinogenic, toxic, and mutagenic effects to human and animals as well as it is reduce the light penetration and that affect the photosynthetic in plants [2]. To reduce the dyes in industrials water effluents chemical, physicalchemical, and biological methods such as photocatalytic degradation, extraction, chemical oxidation, microbiological decomposition, ion exchange, adsorption on activated carbon, combined of adsorption and degradation and ultrasonic decomposition were applied with highly cost [3]. The adsorption on agriculture waste has advantage of low cost and high efficiency as compared to other methods. RHB is synthesized organic dye used in paper, paint, food, leather, pharmaceutical, cosmetic, laboratories as biological stain and so on, this dye has carcinogenic and toxic affect hence the application in food and cosmetic currently restricted[4]. The degradation of RHB on heterogeneous photocatalyst by irradiation with solar [5], ultraviolet[1], and microwave radiation [6] have some interest recently due to high removal percentage but that limit by slow reaction and carcinogenic intermediate compounds [7]. The activated carbon derived from agriculture waste such as Jackfruit peel [8]walnut shell [9], palm shell [10] also used to removal the $\mathrm{RhB}$ with well percentage removal but the activation process and carbonization process additional cost make the activated carbon not economic as compared to direct use of low cost agriculture waste.

The aim of currently article is to introduce the novel low cost adsorbent for removal of RHB from aqueous solution and get the optimum condition of adsorption such as initial concentration, $\mathrm{pH}$, contact time and adsorbent dose. The adsorption isotherm includes Langmuir and Freundlich were used to test the adsorption data. The kinetic data analysis by rate equation to obtain the order of adsorption reaction.

\section{Experimental work RHB}

The RHB dye purchased from sinopharma chemical reagent, china. Was used to prepare the $1000 \mathrm{mg} / \mathrm{L}$ stock solution by dissolving $1 \mathrm{~g}$ of dye in $1 \mathrm{~L}$ of distilled water and then dilution to required concentration. The wavelength at maximum absorbance $\lambda_{\max }$ determined by scanning the wavelength and found to be $550 \mathrm{~nm}$. The chemical structure of RHB is shown in Fig.(1). 
<smiles>CCN(CC)c1ccc2c(-c3ccccc3C(=O)O)c3ccc(=[N+](CC)CC)cc-3oc2c1</smiles>

Fig.(1): structural formula of Rhodamine-B Adsorbent.

The Rhamnus stone was collected from Bismayah, Baghdad, Iraq. The stone was washed with distilled water and then dried at room temperature for 3 days, finally crushed, grinded and sieved. The surface of adsorbent was characterized by FTIR spectra to found the characterized groups affect the adsorption. FTIR spectra were measured by (Shimadzu 8400 S, Japan) spectrophotometer in the range 4000 to $400 \mathrm{~cm}^{-1}$.

\section{Equilibrium experiments}

The adsorption experiments performed by batch model in series of conical flask $(250 \mathrm{~mL})$ where solution of RHB dye $(50 \mathrm{~mL})$ with initial concentration vary from 20 to 120 $\mathrm{mg} / \mathrm{L}$. The $\mathrm{pH}$ adjusted by $0.1 \mathrm{M}$ of $\mathrm{HCl}$ and $\mathrm{NaOH}$. 0.1g Rhamnus stone powder were added to RHB solution and maintained in constant stirring for $70 \mathrm{~min}$ to reach equilibrium. The mixture was then centrifuged and the supernatant concentration determines using spectrophotometer (APEL-303, Japan) at $550 \mathrm{~nm}$. The removal efficiency and the equilibrium uptake of RHB dye $q_{e}$ were calculated according to the equations [3]:

$$
\begin{aligned}
& \% \text { Removal }=\frac{C_{o}-C_{e}}{C_{o}} 100 \\
& q_{e}=\frac{C_{o}-C_{e}}{M} \mathrm{x} \mathrm{V} \ldots \ldots \ldots \ldots \ldots
\end{aligned}
$$

Where, $C_{o}$ is concentration of dye before the adsorption $(\mathrm{mg} / \mathrm{L}), \quad C_{e}$ is equilibrium concentration $(\mathrm{mg} / \mathrm{L}), \mathrm{M}(\mathrm{g})$ adsorbent weight and $\mathrm{V}$ solution volume in liter.

\section{Kinetic experiments}

The $20 \mathrm{mg} / \mathrm{L}$ of $\mathrm{RhB}$ dye solution under the ideal conditions were taken. The concentration of unadsorbed dye measured with time interval
$5 \mathrm{~min}$ and the quantity of RhB adsorbed at time t was calculated by [8]:

$$
q_{t}=\frac{C_{o}-C_{t}}{M} \times \mathrm{V}
$$

Where, $C_{o}$ is original concentration $(\mathrm{mg} / \mathrm{L})$, $C_{t}$ is concentration at time $\mathrm{t}(\mathrm{mg} / \mathrm{L}), \mathrm{M}(\mathrm{g})$ adsorbent weight and $\mathrm{V}(\mathrm{L})$ solution volume.

\section{Result and discussion \\ Characteristics of adsorbent surface}

FTIR spectrum Fig.(2a) shows broad band from 3460.06 to $3176.54 \mathrm{~cm}^{-1}$, that refers to $\mathrm{O}-\mathrm{H}$ alcohol and phenol groups as well as $\mathrm{N}-\mathrm{H}$ stretch for amines [10] and C-O stretch at $1051.13 \mathrm{~cm}^{-1}$. The intense band $2925.81 \mathrm{~cm}^{-1}$ and medium bands at 2858.13 $\mathrm{cm}^{-1}$ exhibit $\mathrm{O}-\mathrm{H}$ carboxylic acid supported by $\mathrm{C}=\mathrm{O}$ at 1741.60 and $1652.88 \mathrm{~cm}^{-1}$ and $\mathrm{C}-\mathrm{O}$ at 1051.13 and $1242.07 \mathrm{~cm}^{-1}$ [3]. Fig.(2b) shows shift the 3460.06 to 3494.99 and disappears $3176.54 \mathrm{~cm}^{-1}$, that proved carboxylic groups affect the adsorption. 


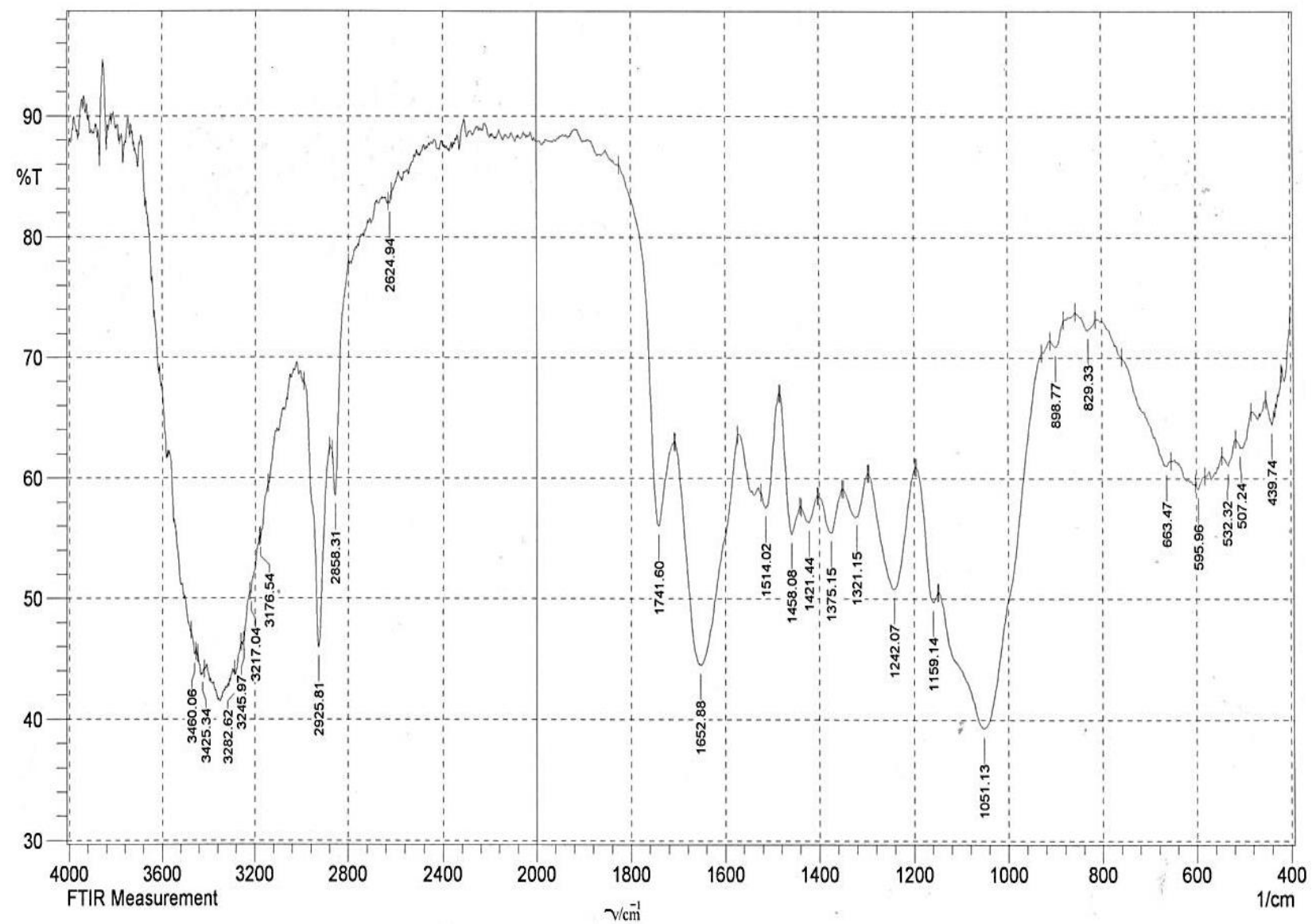

Fig.(2a): FTIR spectrum of Rhamnus stone surface before adsorption.

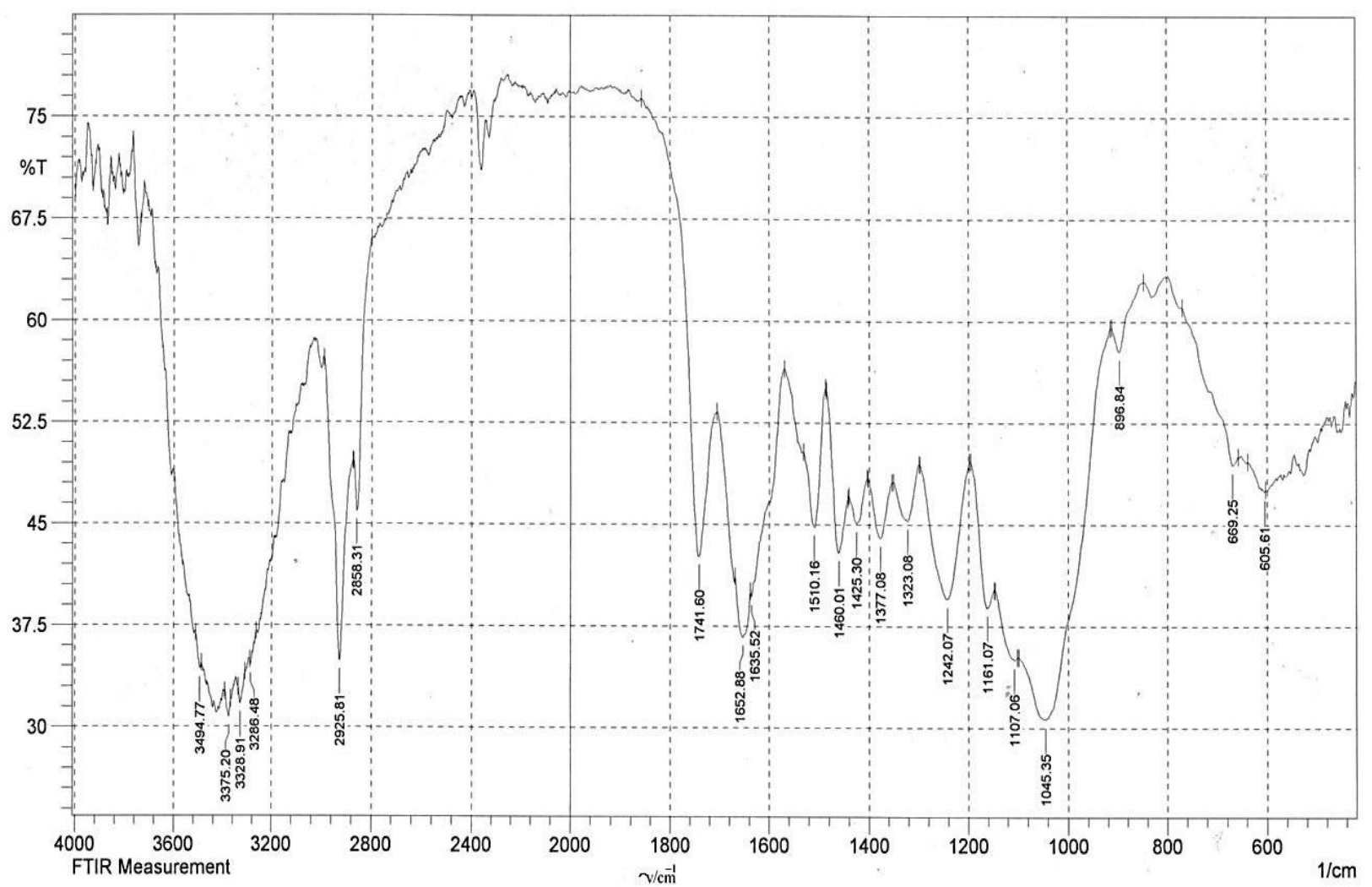

Fig.(2b): FTIR spectrum of Rhamnus stone surface after adsorption. 


\section{Effect of initial pH}

The $\mathrm{pH}$ of the solution affected on electrical charge of adsorbent surface and the ionic forms of adsorbate molecule. Therefore, the adsorption of $\mathrm{RhB}$ (cationic dye) increase with decrease the acidity that is because in acid medium the hydrogen ion competed with $\mathrm{RhB}$ dye molecule and as the number of hydrogen ion reduced more adsorption site will be free to adsorb RhB dye[2]. Figure.3 shows the optimum $\mathrm{pH}$ is 9 .

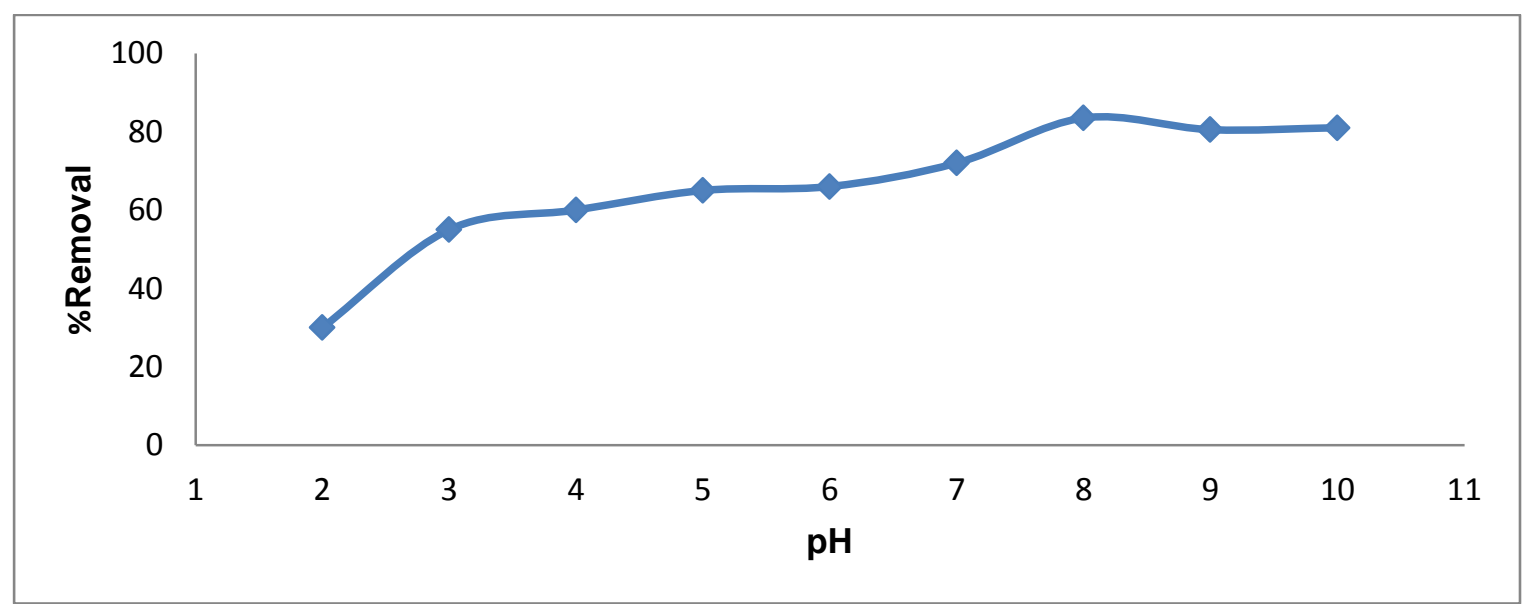

Fig.(3): Effect of pH on percentage removal of 20mg/L initial concentration of RhB dye at 303K.

\section{Effect of adsorbent weight}

The influence of different weight of Rhamnus stone on $\mathrm{RhB}$ percentage removal at a contact time $70 \mathrm{~min}$ was investigated by ranged the Rhamnus stone weight from $0.05 \mathrm{~g}$ to $0.35 \mathrm{~g}$ in $20 \mathrm{mg} / \mathrm{L} \mathrm{RhB}$ solution. Fig.(4) shows increased percentage removal with increasing of Rhamnus stone weight and that is because more surface area implies greater number of adsorbent sites attained by increase the weight of Rhamnus stone[8].

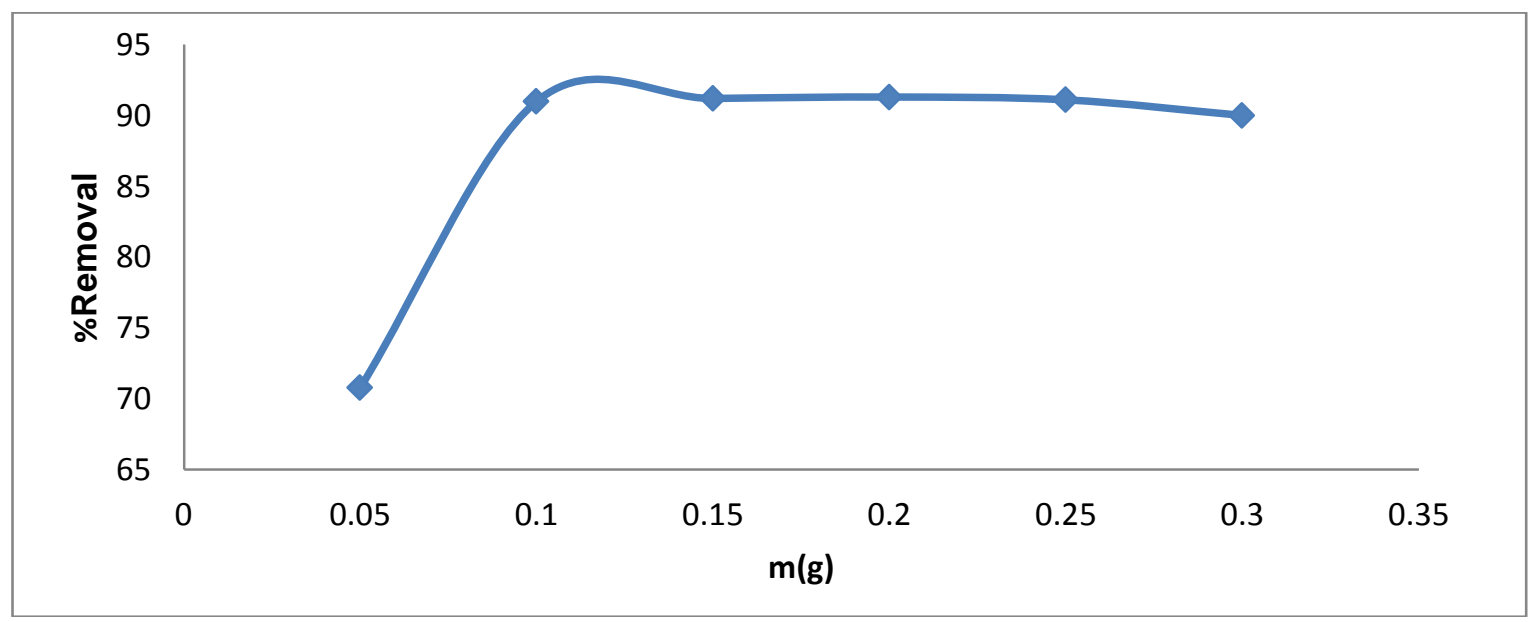

Fig.(4): Effect of adsorbent weight on percentage removal of 20mg/L initial concentration of RhB dye at $303 K$. 


\section{Effect of contact time}

The removal of RhB dye by adsorption on Rhamnus stone was studied as a function of contact time, and percentage removal plotted against time at 303K. Fig.(5) shows the adsorption rate of $\mathrm{RhB}$ onto Rhamnus stone is fast at the beginning and become constant after $70 \mathrm{~min}$.

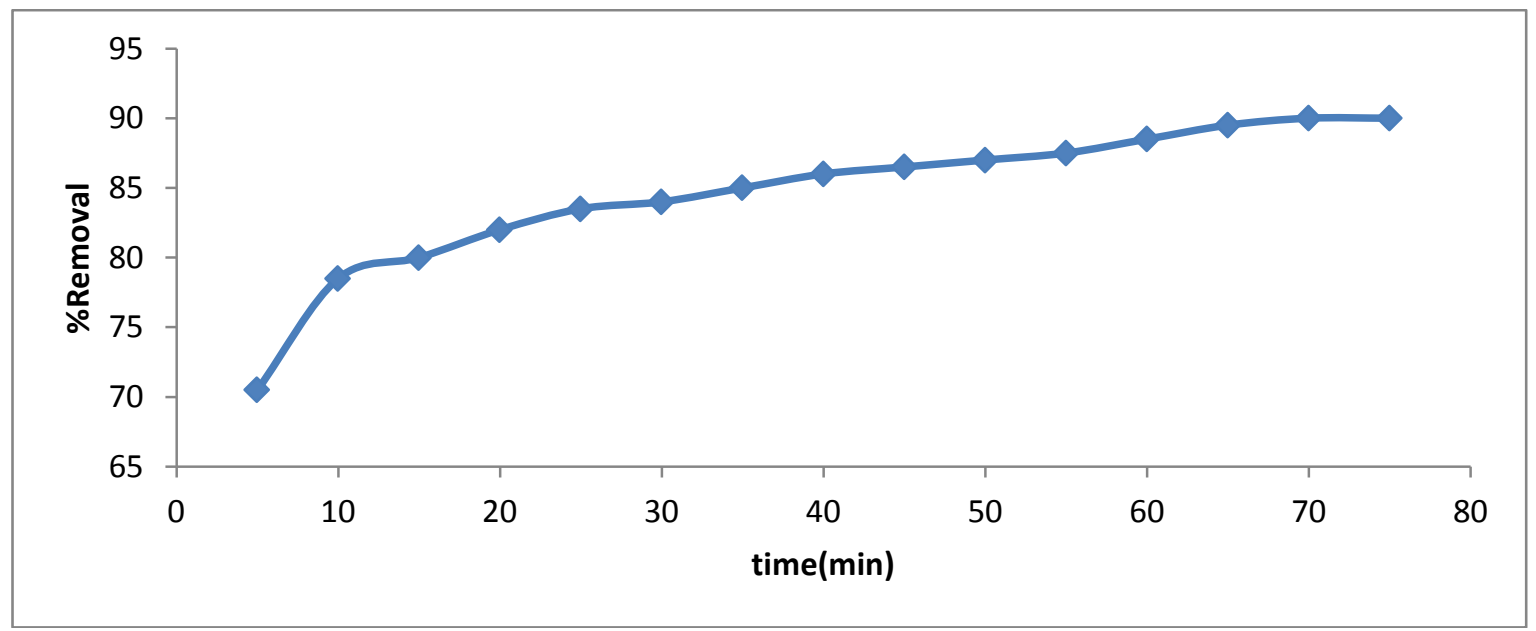

Fig.(5): Effect of contact time on percentage removal of 20mg/L RhB dye at 303K.

\section{Effect of initial concentration}

The availably of free adsorption sites reduced by increasing the initial concentration of dye therefore the removal percentage decreasing and the amount of dye removed increasing [11]. Fig.(6) reveal that $20 \mathrm{mg} / \mathrm{L}$ is the ideal initial concentration of RhB.

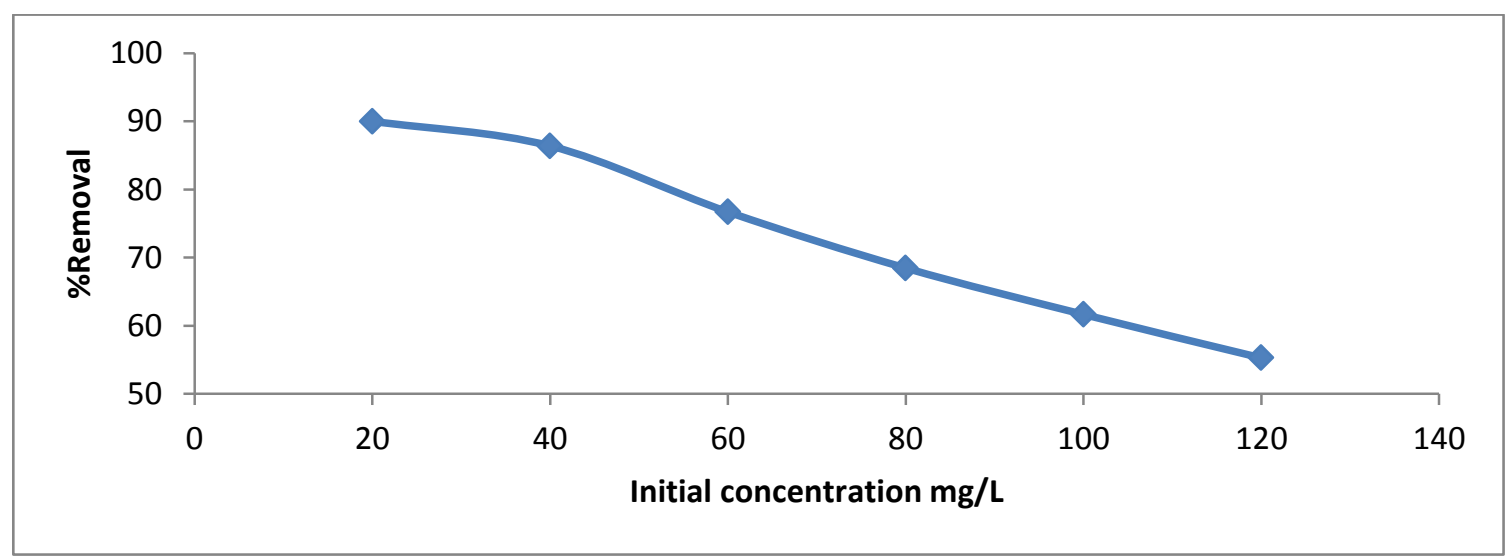

Fig.(6): Effect of initial concentration on percentage removal of RhB dye at $303 \mathrm{~K}$.

\section{Equilibrium isotherm}

The relationship between the quantity of dye molecules adsorbed per unit mass of adsorbent and its equilibrium concentration at constant temperature is called the adsorption isotherm. The adsorption isotherms are basic requirement for designing any adsorption system. The experimental data were fitted to
Langmuir and Fruendlich isotherms. The Langmuir assumes the adsorbent surface is uniform with limit number of active site and no more adsorption take place after formation monolayer [2,12]. Freundlich assumes heterogeneous surface and the concentration of adsorbate affect the adsorption capacity [13]. The linear form of Langmuir equation and 
separation factor defined by Weber and Chakkravorti are given by following equations [4]:

$$
\begin{aligned}
& \frac{C_{e}}{q_{e}}=\frac{1}{q_{m} K_{L}}+\frac{C_{e}}{q_{m}} \\
& R_{L}=\frac{1}{1+K_{L} C_{o}} \ldots . .
\end{aligned}
$$

Where $C_{e}(\mathrm{mg} / \mathrm{L}) \mathrm{RhB}$ dye concentration at equilibrium, $q_{e}(\mathrm{mg} / \mathrm{g})$ equilibrium uptake, $q_{m}$ and $K_{L}$ are Langmuir constants obtained from plot of $\frac{C_{e}}{q_{e}}$ versus $C_{e}$ Fig.(7). The value of dimensionless separation factor $R_{L}$ ranged from 0.2644 to 0.0565 this indicate favorable adsorption of $\mathrm{RhB}$ dye onto Rhamnus stone [10].

The Freundlich isotherm in the logarithmic form written as follows [9]:

$$
\log q_{e}=\log K_{F}+\frac{1}{n} \log C_{e}
$$

Where $C_{e}(\mathrm{mg} / \mathrm{L}) \mathrm{RhB}$ dye concentration at equilibrium, $q_{e}(\mathrm{mg} / \mathrm{g})$ equilibrium uptake. From slope and intercept of figure.8.(plot of $\log q_{e}$ verses $\log C_{e}$ ) the Freundlich constants $K_{F}$ and $\frac{1}{n}$ calculated and the result summarized in Table (1). The heterogeneity factor $\frac{1}{n}$ value near to zero that conform heterogeneous distribution of adsorption sites on the adsorbent surface [2,14]. The adsorption of $\mathrm{RhB}$ dye on to Rhamnus stone follows Langmuir as well as Freundlich model and the Langmuir adsorption model appears better fit
$\left(R^{2}=0.996\right)$ than the Freundlich model $\left(R^{2}=0.959\right)$ and the maximum adsorption capacity increased with increased temperature exhibit endothermic process[15] .

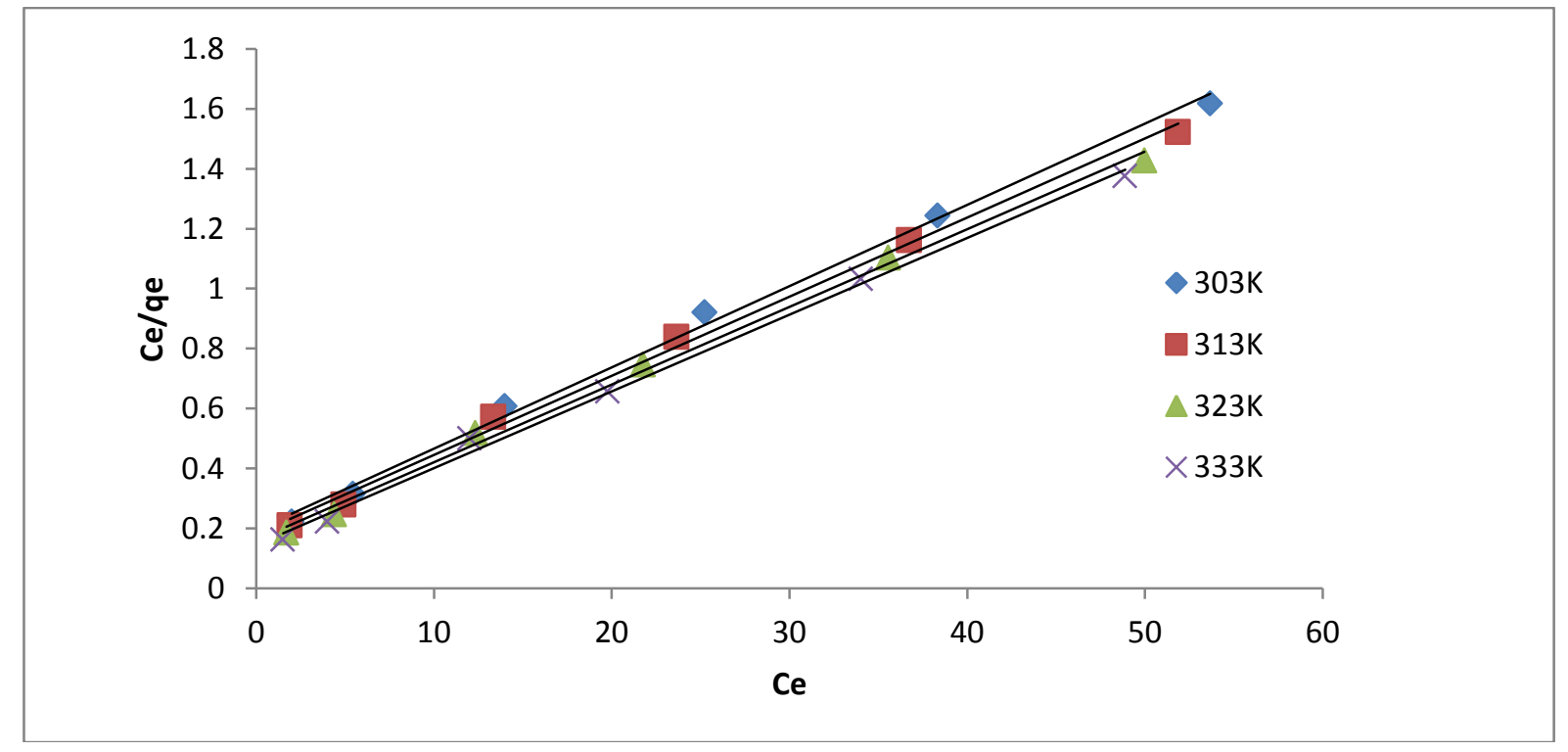

Fig.(7): Langmuir adsorption isotherm of RhB onto Rhamnus stone. 


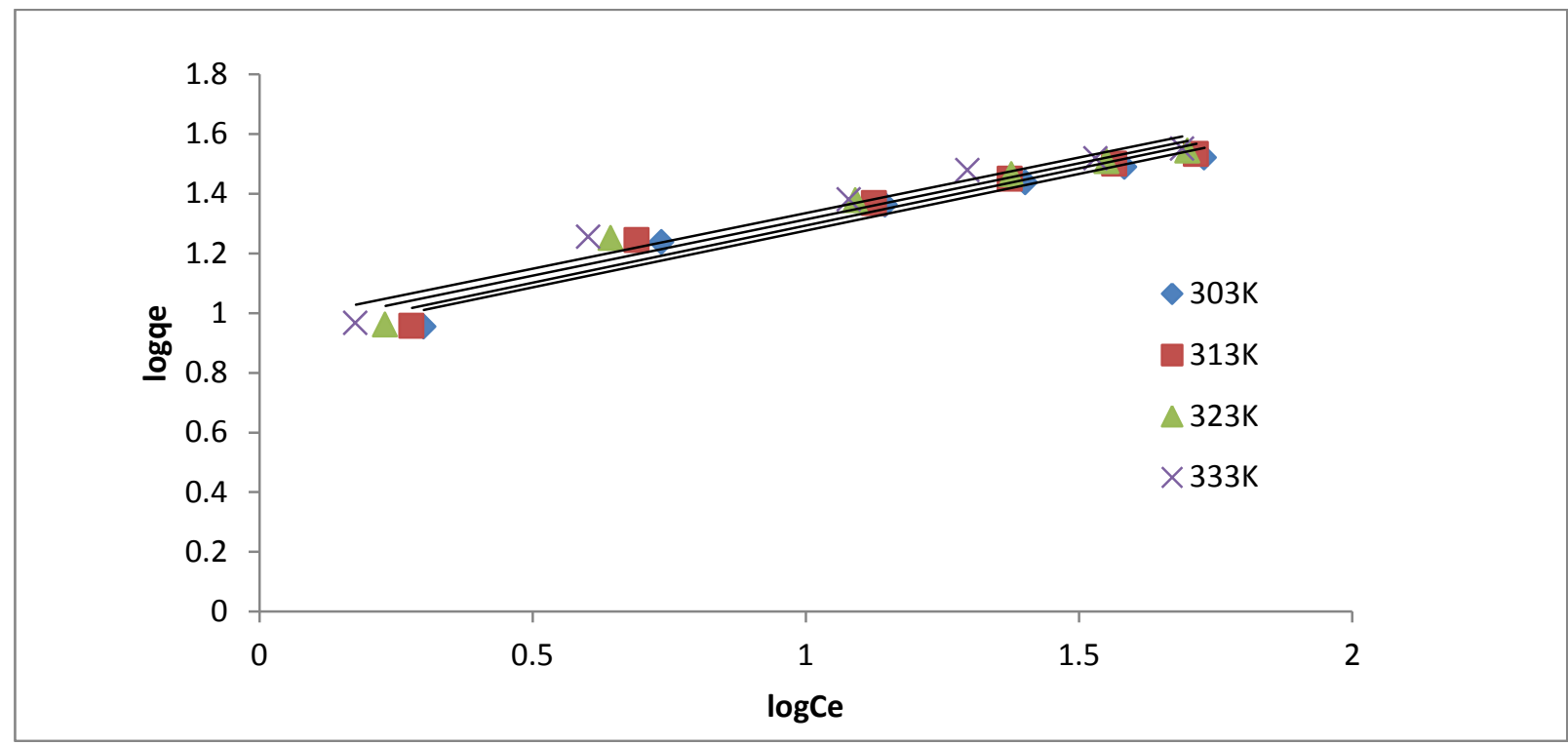

Fig.(8):Freundlich adsorption isotherm of RhB onto Rhamnus stone.

Table (1)

Isotherms constants and correlation coefficient.

\begin{tabular}{|c||c|c||c||c||c|c||}
\hline \hline \multirow{2}{*}{$\begin{array}{c}\text { Temp. } \\
(\mathbf{K})\end{array}$} & \multicolumn{2}{|c|}{ Langmuir isotherm } & \multicolumn{3}{c|}{ Freundlich isotherm } \\
\cline { 2 - 7 } & $\boldsymbol{K}_{\boldsymbol{L}}(\mathbf{L} / \mathbf{m g})$ & $\boldsymbol{q}_{\boldsymbol{m}}(\mathbf{m g} / \mathbf{g})$ & $\boldsymbol{R}^{\mathbf{2}}$ & $\boldsymbol{K}_{\boldsymbol{F}}\left(\mathbf{m g} / \mathbf{g}\left(\frac{\mathbf{L}}{\mathbf{m g}}\right)^{\mathbf{1} \boldsymbol{n}}\right)$ & $\mathbf{1 / n}$ & $\boldsymbol{R}^{\mathbf{2}}$ \\
\hline \hline 303 & 0.1391 & 36.90 & 0.9963 & 7.8578 & 0.3811 & 0.9594 \\
\hline 313 & 0.1454 & 37.88 & 0.9962 & 8.1508 & 0.3828 & 0.9541 \\
\hline 323 & 0.1602 & 38.61 & 0.9964 & 8.6716 & 0.3757 & 0.9533 \\
\hline 333 & 0.1764 & 39.06 & 0.9963 & 9.1854 & 0.3720 & 0.9514 \\
\hline \hline
\end{tabular}

\section{Kinetic studies}

To understand the mechanism of adsorption reaction, the kinetics experimental observation data was fitted to pseudo-first order (Lagergren equation), and (Ho and McKay) pseudo-second order. The linear form of Lagergren equation formulated as the following [16]:

$$
\log \left(q_{e}-q_{t}\right)=\log q_{e}-\frac{k_{1}}{2.303} \mathrm{t}
$$

Where $q_{e}$ and $q_{t}$ the adsorption capacity at equilibrium and time $t$ respectively. From the plots of $\log \left(q_{e}-q_{t}\right)$ against the time $\mathrm{t}$ for $20 \mathrm{mg} / \mathrm{L}$ concentration of $\mathrm{RhB}$ dye at $303 \mathrm{~K}$ (Figure.9), the value of $k_{1}$ rate constant, calculated equilibrium uptake $q_{e}$ and correlation coefficient obtained and listed in Table (2).

The (Ho and McKay 1999) pseudo-second order equation written as follows [17]:

$$
\frac{t}{q_{t}}=\frac{1}{k_{2} q_{e}^{2}}+\frac{1}{q_{e}} \mathrm{t}
$$

A linear plot of $\frac{t}{q_{t}}$ against time give the straight line and from the slope and intercept value of $k_{2}$ and $q_{e}$ can be calculated. The initial adsorption rate $h_{o}$ at various initial concentrations is related in the following equation [14]:

$$
h_{o}=k_{2} q_{e}^{2}
$$

The determination of suitable kinetic model for the adsorption reaction by comparing the correlation coefficient is restricted to linear kinetic model. Therefore, the sum of error squares used to indicate the most suitable kinetic mode [18]:

$$
\operatorname{SSE}(\%)=\sqrt{\frac{\sum\left(q_{e, \exp }-q_{e, c a l}\right)^{2}}{N}}
$$

Where SSE is sum of error squares, $q_{e, \exp }$ experimental equilibrium uptake, $q_{e, c a l}$ calculated equilibrium uptake and $\mathrm{N}$ number of data point. The result in table. 2 shows 
correlation coefficient close to 1 and sum of error squares close to zero for pseudo-second order model that conform the adsorption of $\mathrm{RhB}$ dye onto Rhamnus stone is follows pseudo-second order under the condition used in this study.

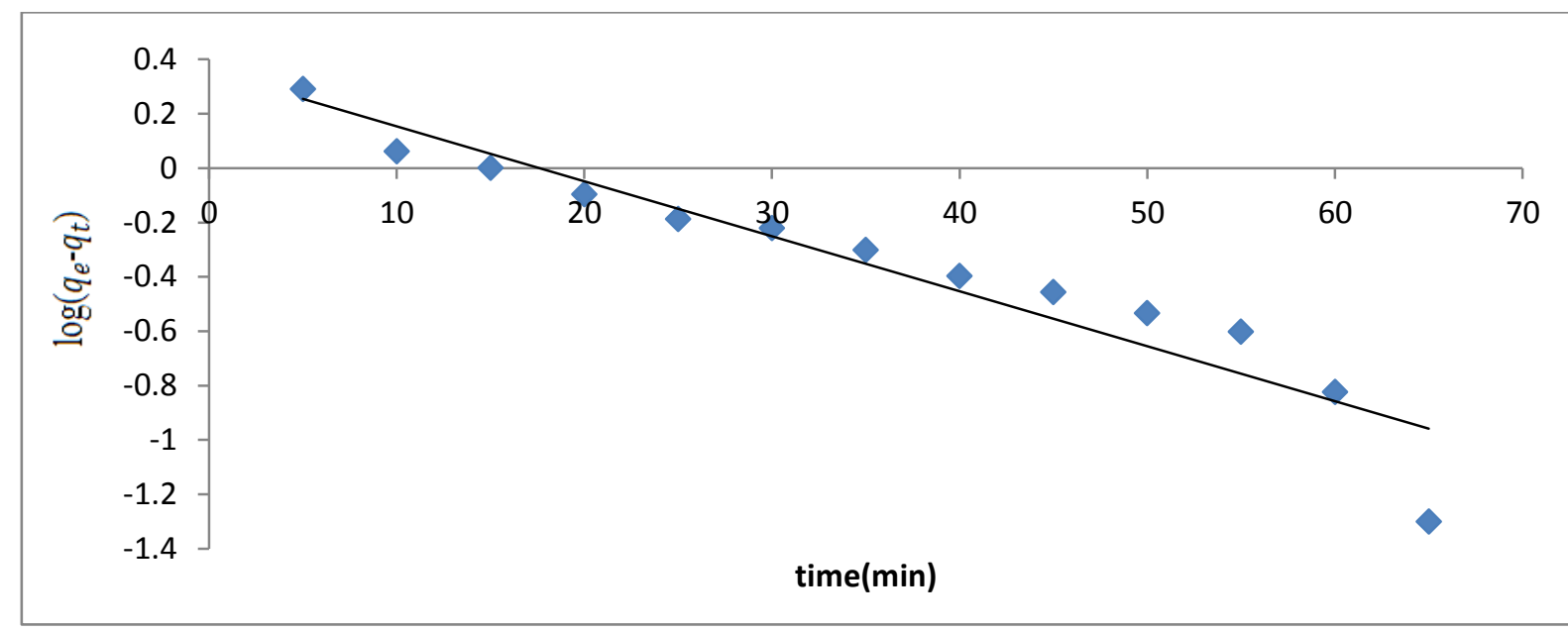

Fig.(9):Pseudo-first order of RhB dye onto Rhamnus stone at $303 \mathrm{~K}$ using 20mg/L RhB.

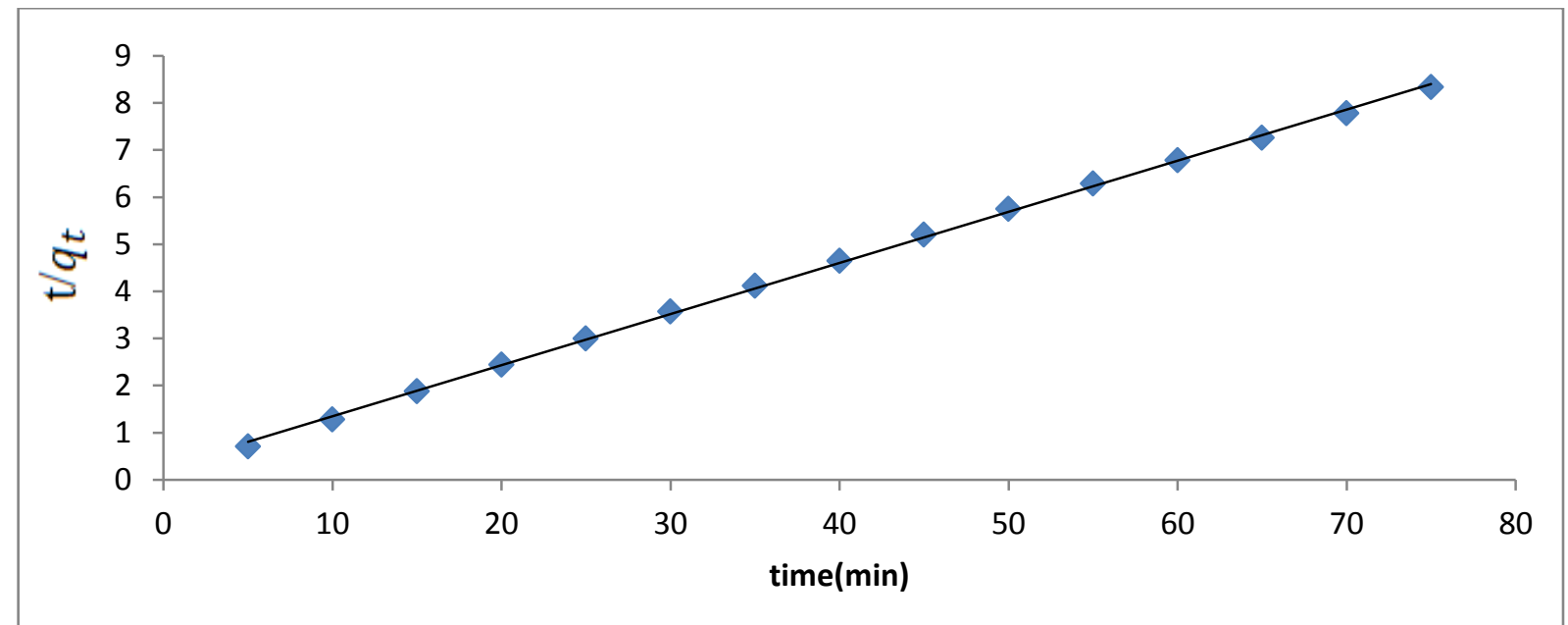

Fig.(10): Pseudo-second order of RhB dye onto Rhamnus stone at 303K using 20mg/L of RhB.

Table (2)

Kinetic results of $20 \mathrm{mg} / \mathrm{L} \mathrm{RhB}$ dye on Rhamnus stone at $303 \mathrm{~K}$.

\begin{tabular}{|c|c|c|c|c|c|c|c|c|}
\hline \multirow{2}{*}{$\begin{array}{l}q_{e, e x p} \\
\mathrm{mg} / \mathrm{g}\end{array}$} & \multicolumn{4}{|c|}{ Pseudo-first order } & \multicolumn{4}{|c|}{ Pseudo-second order } \\
\hline & $k_{1}\left(\min ^{-1}\right)$ & $\begin{array}{l}q_{e, c a l} \\
\mathrm{mg} / \mathrm{g}\end{array}$ & $R^{2}$ & $\%$ SSE & $\begin{array}{c}k_{2} \\
\text { g.mg }{ }^{-1} . m i n^{-1}\end{array}$ & $\begin{array}{l}q_{e, c a l} \\
\mathrm{mg} / \mathrm{g}\end{array}$ & $R^{2}$ & $\%$ SSE \\
\hline 9 & 0.0465 & 2.26 & 0.907 & 6.73 & 0.0456 & 9.2 & 0.999 & 0.2 \\
\hline
\end{tabular}

\section{Thermodynamic studies}

Thermodynamic parameters are calculated by following equations [10]:

$$
\begin{aligned}
& K_{c}=\frac{C_{a d s}}{C_{e}}=\frac{C_{o}-C_{e}}{C_{e}}=\frac{C_{o}}{C_{e}}-1 \\
& \Delta G^{o}=-\mathrm{RT} \ln K_{c}
\end{aligned}
$$

$$
\ln K_{C}=\frac{\Delta S^{o}}{R}-\frac{\Delta H^{o}}{R T}
$$

Where, $K_{c}$ equilibrium constant, $C_{o}(\mathrm{mg} / \mathrm{L})$, $C_{a d s}(\mathrm{mg} / \mathrm{L})$, and $C_{e}(\mathrm{mg} / \mathrm{L})$ represent the dye original dye concentration, concentration of adsorbed dye and remaining concentration in solution at equilibrium, respectively. The $\Delta G^{o}$, 
$\Delta H^{o}$ and $\Delta S^{o}$ are change in free energy, enthalpy and entropy respectively. $\mathrm{R}$ gas constant $\left(8.314 \mathrm{~J} . \mathrm{mol}^{-1} \cdot \mathrm{K}^{-1}\right)$ and $\mathrm{T}(\mathrm{K})$ solution absolute temperature. The $\Delta G^{o}$ obtained have negative sign that indicates the adsorption process was spontaneous and from slope and intercept of van't Hoff plot Fig.(11),
$\Delta H^{o}$ and $\Delta S^{o}$ are calculated. The thermodynamic results summarized in Table(3) shows positive value of enthalpy indicates endothermic adsorption reaction and positive value of entropy indicate increase in randomness.

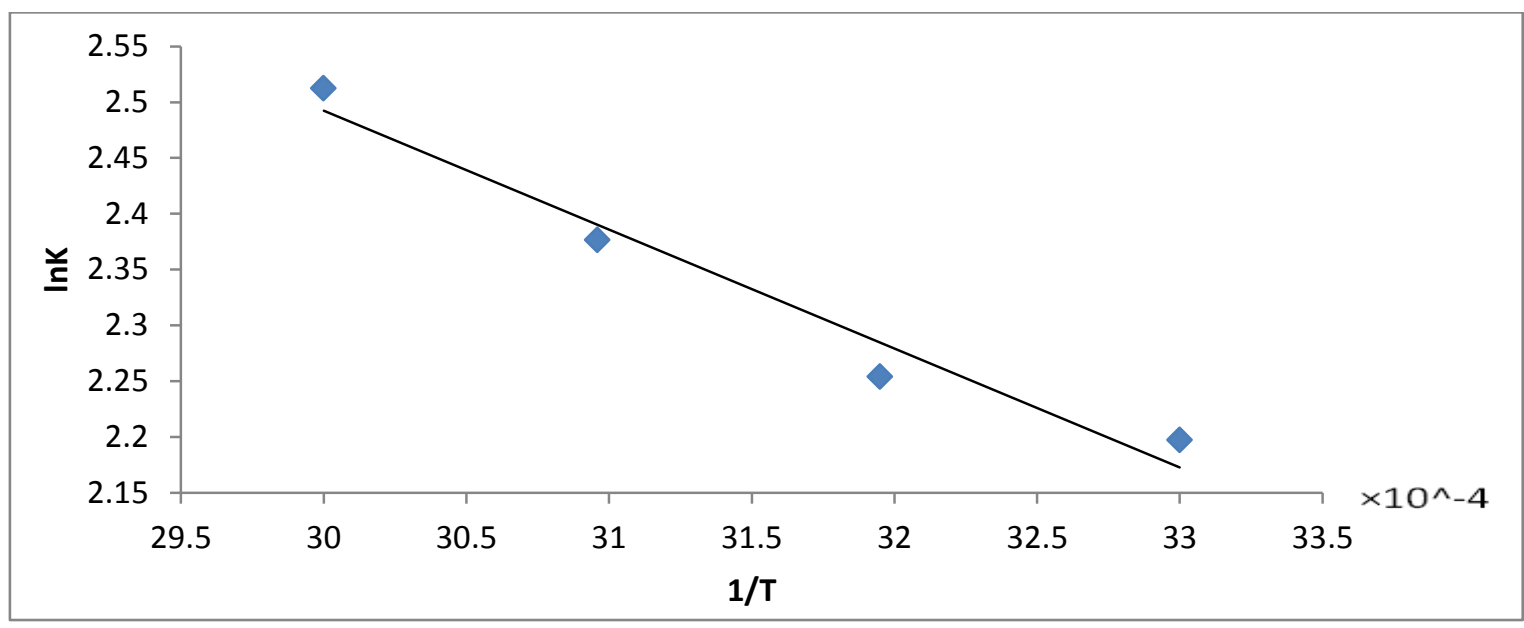

Fig.(11): Van't Hoff plot of RhB dye onto Rhamnus stone.

Table (3)

Values of thermodynamic parameters for the adsorption of RhB on the Rhamnus stone at different temperatures.

\begin{tabular}{|c|c|c|c|}
\hline $\mathbf{T}(\mathbf{K})$ & $\Delta \mathrm{G}\left(\mathrm{kJ} . \mathrm{mol}^{-1}\right)$ & $\Delta \mathrm{H}\left(\mathrm{kJ} . \mathrm{mol}^{-1}\right)$ & $\Delta \mathrm{S}\left(\mathrm{J} . \mathrm{mol}^{-1} \cdot \mathrm{K}^{-1}\right)$ \\
\hline 303 & -5.535 & \multirow{4}{*}{+8.8} & \multirow{4}{*}{+47.27} \\
\hline 313 & -5.865 & & \\
\hline 323 & -6.381 & & \\
\hline 333 & -6.955 & & \\
\hline
\end{tabular}

\section{Conclusion}

The results exhibit that Rhamnus stone is an excellent new low cost adsorbent for removal of $\mathrm{RhB}$ dye from aqueous solution. The experimental equilibrium data obeyed for Langmuir as well as Freundlich isotherms with better fit to Langmuir isotherm. Thermodynamic studies shows the adsorption process spontaneous and endothermic.

\section{Reference}

[1] Natarojon T.S., Thomas M., Natarojon K. and Rajesh, "study on UV-LED/TiO process for degradation of Rhodamine $\mathrm{B}$ dye" Chemical Engineering J, 169:126-134, 2011.

[2] Vijay K.G., Tamilarasan R., and Dharmendirakumar M, "Adsorption, Kinetic, Equilibrium and Thermodynamic studies on the removal of basic dye Rhodamine B from aqueous solution by the use of natural adsorbent perlite" mater. Environ. sci J, 3(1), 157-170, 2012.

[3] Ahmed R. and Kumar R., "Adsorption studies of hazardous malachite green onto treated ginger waste" Environmental mangement. J, 91, 1032-1038, 2010.

[4] Barka N, Qourzal S, Assabbane A, Nounah A. and Ichou. Y, "Factors influencing the photocatalytic degradation of Rhodamine $\mathrm{B}$ by $\mathrm{TiO}_{2}$-coated non-woven paper" Photochemisty and Photobiology J, 195, 346-351, 2008.

[5] Park Y, Yulyi N., Pradhan D, Kimin B. and Sohn, Y, "Adsorption and UV/Visible Photocatalytic performance of $\mathrm{BiOI}$ for methyl orange, Rhodamine $\mathrm{B}$ and 
methylene blue: Ag and Ti-loading effects" Cryst Engcom. J, 16, 3155-3167, 2014.

[6] He Z, Sun C., Yang S., Ding Y. and Wang, Z., "Photocatalytic degradation of Rhodamine $\mathrm{B}$ by $\mathrm{Bi}_{2} \mathrm{WO}_{6}$ with electron accepting agent microwave irradiation: mechanism and pathway" Hazardous materials. J, 162, 1477-1486, 2009.

[7] Giwa A, Nkeoye P.O and Kolowole E.G, "Solar Photocatalytic degradation of reactive yellow 81 and reactive violet in aqueous solution containing semiconductor oxides" International J. of Applied Science and Technology, 2(4), 90-105, 2012.

[8] Inbaraj B.S. and Sulochana, N., "Use of jackfruit peel carbon for adsorption of Rhodamine B a basic dye from aqueous solution" Indian journal of chemical Technology, 13,17-23, 2006.

[9] Sumanjit J., Walia T.P. and Kansal I, "Removal of Rhodamine B by adsorption on walnut shell charcoal" Surface. Sci. Technol. J, 24(3), 179-193, 2008.

[10] Mohammadi M., Hassani A.J., Mohamed A.R and Najafpour, G., "Removal of Rhodamine $\mathrm{B}$ from aqueous solution using palm shell-based activated carbon: adsorption and kinetic studies" Chem. Eng. Data. J, 55, 5777-5785, 2010.

[11] Almeida C.A.P, Dedacher N.A, Downs A.J and Mello "Removal of methylene blue from colored effluents by adsorption on montmorillanite clay" colloid and interface science J,332,46-53, 2009.

[12] Langmuir I., "The adsorption of gases on plane surfaces of glass, mica and platinum" Am. Chem. J, 40(9), 1361-1403, 1918.

[13] Freundlich H., "Over the adsorption in solution" Z. Phys. Chem. J, 57, 385-470, 1906.

[14] Doke K.M., Chavan M., Nalawade R. and Khan E.M., "Kinetics and Equilibrium Isotherm for adsorption of Basic Blue 9 Dye onto Activated Charcoal prepared from Bhagar seed husk", JMES J, 4(3), 374-383, 2013.

[15] Seow T.W. and Lim C.K, "Removal of dye by adsorption: A Review" International J. of Applied Engineering Research, 11(4), 2675-2679, 2016.
[16] Al-Kinani, E.M. "Studies on removal of hexavalent chromium ion from aqueous solution using polyaniline composite", J. of Al-Nahrain University ,19(2), 58-68, 2016.

[17] Ho Y.S. and Mckay G. "Pseudo-second order model for sorption process" Process biochemistry J., 34,451-465. 1999.

[18] Abbas A.M., Mohammed Y.I. and Hamdan, T.A., "Adsorption kinetic and thermodynamic study of congo red dye on synthetic zeolite and modified synthetic zeolite" Ibn Al-Haitham. J. for Pure and Applied Sci, 28(1), 54-72, 2015.

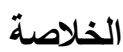

تم في هذه الدراسة استعمال نوى النبق كمادة مازة لأمنزاز

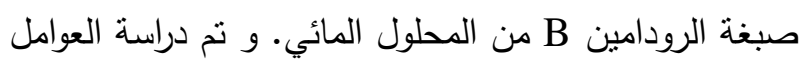
المؤثرة على الامتزاز مثل كمية المادة المازة، زمن التماس، الدالة الحامضية و نركيز المادة الممتزة بطريقة الوجبة. كذلك الكئك تم دراسة حركية الامتزاز و وجد انها تخضع للمعادلة الحركية من الدرجة الثانية الكاذبة. و بعدها نم تحليل بيانات الاتزان باستخدام ايزوثرمات لانكماير و فروندليش وانثارت النتائج

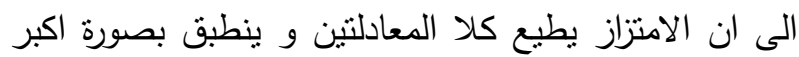

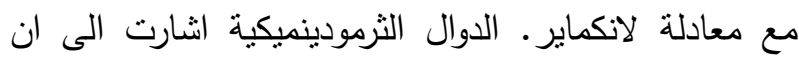
التفاعل تلقائي و ماص للحرارة. 